\title{
Forecasting long-term energy demand of Croatian transport sector
}

\author{
Tomislav Pukšec ${ }^{\mathrm{a}, *}$, Goran Krajačić ${ }^{\mathrm{a}}$, Zoran Lulića, Brian Vad Mathiesen ${ }^{\mathrm{b}}$, Neven Duića \\ a University of Zagreb, Faculty of Mechanical Engineering and Naval Architecture, Ivana Lučića 5, Croatia \\ ${ }^{\mathrm{b}}$ Department of Development and Planning, Aalborg University, A.C. Meyers Vænge 15, DK-2450 Copenhagen SV, Denmark
}

\section{A R T I C L E I N F O}

\section{Article history:}

Received 14 September 2012

Received in revised form 29 April 2013

Accepted 30 April 2013

Available online 27 June 2013

\section{Keywords:}

Energy demand

Transport sector

Bottom-up modelling

Electrification

Modal split

\begin{abstract}
A B S T R A C T
The transport sector in Croatia represents one of the largest consumers of energy today, with a share of almost one third of the country's final energy demand. Considering this fact, it is very challenging to assess future trends influencing that demand. In this paper, long-term energy demand predictions for the Croatian transport sector are presented. Special emphasis is given to different influencing mechanisms, both legal and financial. The energy demand predictions presented in this paper are based on an end-use simulation model developed and tested with Croatia as a case study. The model incorporates the detailed modal structure of the Croatian transport sector, including road, rail, air, public and water transport modes. Four long-term energy demand scenarios were analysed till the year 2050; frozen efficiency, implementation of EU legislation, electrification and modal split. Based on that analysis, significant savings can be achieved through energy efficiency improvements, electrification of personal vehicles fleet as well as gradual modal split. Comparing the frozen efficiency scenario and electrification scenario for the year 2050, it can be concluded that energy consumption, with the heavy electrification of personal vehicles fleet, can be cut by half.
\end{abstract}

() 2013 Elsevier Ltd. All rights reserved.

\section{Introduction}

The transport sector, as one of the most propulsive sectors, represents an important contribution to the energy balance in Croatia. Over the past ten years, the final energy demand of the Croatian transport sector has grown by more than $70 \%$, which can be explained by constant fleet expansion, followed by high economic growth [1]. Another important factor that has induced increased energy consumption is the increase in capital infrastructure, especially modern highways. To plan ahead and model future energy systems, predicting future energy demand seems as the first logical step [2]. As already mentioned, the high significance of Croatia's energy balance makes the transportation sector one of the most interesting to analyse [3]. One of the intentions of this research was to propose a clear and rational energy demand model. Unfortunately, there are only a few long-term energy demand scenarios that involve the Croatian transport sector. The most important one is the official national energy strategy, which provides an overview of the country's energy demand scenarios using a sectoral approach. It offers future energy demand projections for

\footnotetext{
* Corresponding author.

E-mail addresses: tomislav.puksec@fsb.hr (T. Pukšec), goran.krajacic@fsb.hr (G. Krajačić), zoran.lulic@fsb.hr (Z. Lulić), bvm@plan.aau.dk (B.V. Mathiesen), neven.duic@fsb.hr (N. Duić).
}

all economic sectors for the years 2020 and 2030 [4]. In the results section of this paper, the results obtained from this study will be compared with the official national energy strategy for the years 2020 and 2030.

The methodology, described in this paper, was adopted to construct a bottom-up long-term energy demand planning strategy, which was applied to the Croatian transport sector as a case study. Thus, the strategy is focused on the end users, and by aggregating all transport subsectors total energy demands are calculated. The presented planning strategy is structured as an energy demand of transport (EDT) model, which is based in MS Excel and can be modified and structured as the user wishes. The EDT model can also be applied to any other country and its transportation sector provided that it can follow the input data pattern. For the purposes of this paper, the EDT model was structured to predict the future energy demand till the year 2050. Different approaches were considered [5-9] for the development of this model, but a bottom-up approach was selected as the most suitable one because it allows users to have a wider view of the whole sector and provides the opportunity to implement different types of mechanisms, such as technology switching or legal regulation, in a more detailed way [10-13]. One of the main objectives of this research was to try to quantify all such mechanisms in terms of energy consumption. With this approach to demand-side modelling, higher-quality data and results can be obtained and used as input data for all future research on advanced system analysis [14-16]. 
A top-down approach was incorporated and partially implemented using the EDT model but only to observe the energy demand projection left to economic growth. Similar models and studies [17-20] have been performed to compare the two approaches (top-down and bottom-up) and to determine the best possible solution. One of the key challenges in future energy demand planning is trying to decouple energy consumption and economic growth. With a bottom-up approach, such decoupling can be performed more easily, where focus is on end use. Predicting future energy demand more precisely and quantifying and describing all possible future energy savings leaves room for higher penetration by renewable energy sources [21]. Today, long-term energy demand planning cannot be left to "trend analysis". Different energy policies and technologies will have a significant impact on future transport systems [22]. Thus, a bottom-up model based on the scenario approach can provide different paths to future energy systems.

The EDT model has five transport subsectors: road, rail, air, seariver and public transport. Because the model is Excel-based, additional subsectors can be added or some of the existing ones can be deleted. A separate mode is created for each subsector to describe all of the specific factors influencing future energy demand. To calculate the total final energy demand of a transport sector, the final energy demands of all of the subsectors are summed in the model.

In the case of Croatia, certain boundary conditions and specific factors were incorporated to describe the country's transport sector. These factors include coastal transportation and special coverage of urban public transportation. One of the major boundary conditions was the exclusion of bunker fuel in both air and sea coastal transportation. For the purposes of this research, the official Croatian energy balance [1] and statistics [23] were followed to provide a consistent basis for all future research and results.

\section{Methodology}

The EDT model operates on the principle of covering and analysing every subsector separately and then summing their contributions in the final energy demand balance. A cross-subsector connection only occurs when calculating the modal split between road, air and rail transportation. The first step is to import all statistical data into the model to initiate the necessary calculations. The model operates based on the reference year. To model the reference year, significant input data are required for all transportation modes. The reference year is primarily used to test the methodology. In that case model's output data are known.

Based on a given reference year, all of the missing input data can be tested and verified and the missing initial variables can be calculated, which would later be used in the section designed for energy demand prediction. Due to a lack of certain input data, calculating the missing variables through a reference year was the only way to proceed with this research. This includes specific consumptions, travelled distances and vehicle type shares. Finally, after the methodology is tested, different scenarios can be set and long-term energy demands can be calculated. An overview of the model and its logic is provided in Fig. 1. The results presented in this

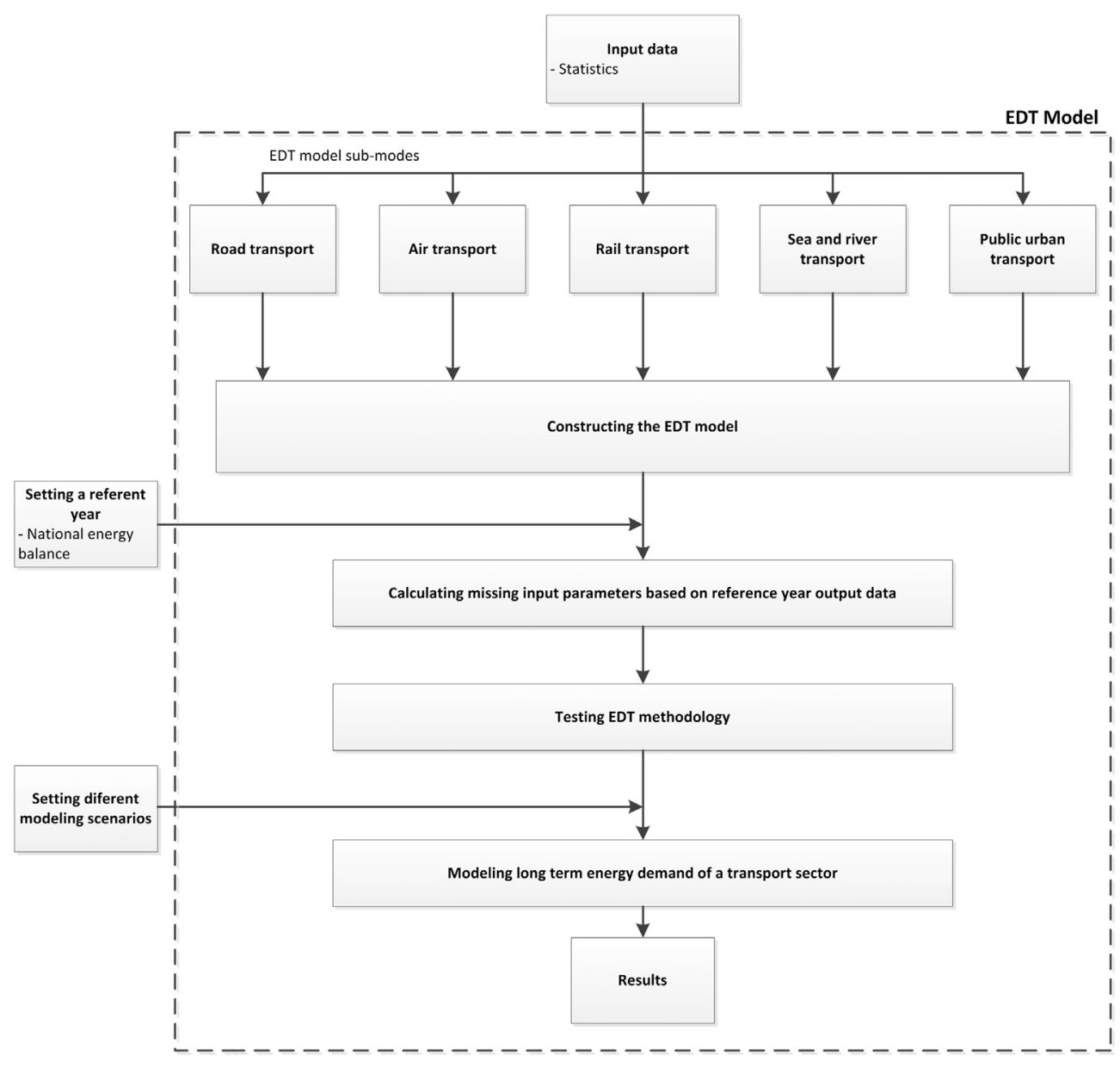

Fig. 1. Overview of the EDT model. 
paper were compared with the Croatian national energy strategy. Because the EDT model predicts future energy demand till the year 2050, a full comparison with the Croatian national energy strategy was not possible because it ends in the year 2030. The basic methodology of the EDT model, considering its subsectors, is presented in the following sections.

\subsection{Road transport}

Almost 90\% of all final energy demand regarding the Croatian transport sector is due to road transport. Thus, modelling road transport and its future energy demand is the most important goal of the EDT model. Accordingly, this part of the model is also the most detailed one in terms of methodology. Road transport is modelled based on the number of vehicles exiting and entering the system, their efficiency, usage, technology and fuel consumption. Vehicles include motorcycles, personal vehicles, buses, trucks weighing less than 3.5 tonnes and trucks weighing more than 3.5 tonnes. The Croatian Bureau of Statistics was used as the starting point to unify all input data and make the results comparable to any future study. Summing the consumption of all categories yields the total final energy demand of the road transport subsector. The EDT model can model energy efficiency improvements, technology switching and fuel switching. The technologies currently available in the model are vehicles with internal combustion engines, electric vehicles and hybrid vehicles.

Regarding fuel types, the EDT model works for gasoline, diesel, liquefied petroleum gas, compressed natural gas, electricity, biofuels as well as synthetic fuels. The final annual energy demand of each category in road transportation is calculated based on the following formula, where $i$ represents vehicle type:

$D_{i}^{z}=\sum_{i=1}^{n}\left(E_{i}^{z} \cdot M_{i}^{z} \cdot C v_{i} \cdot P_{i}^{z} \cdot C m_{i} \cdot Q_{i}\right) / 10^{11}$

The total number of each type of vehicle is calculated based on the existing vehicles in the system and the vehicles that are entering and exiting the system continuously every year:

$E_{i}^{z}=E_{i}^{z-1}+N_{i}^{z}-C f_{i}^{z}$

Technology as well as fuel switching is modelled by considering all of the vehicles entering the system. Different scenarios depending on various fuel mixtures can be calculated by the EDT model. In this case, the most interesting vehicles are personal vehicles, for which the greatest extent of technology switching in the forthcoming years can be expected. The number of personal vehicles entering the system is calculated based on two approaches. First, the number of alternative personal vehicles entering the system (electric and hybrid vehicles) is calculated. Based on their dynamics, the number of other personal vehicles that run on conventional fuels (gasoline, diesel and liquefied petroleum gas) entering the system is calculated. Thus, for every alternative vehicle entering the system, a certain percentage of conventional vehicles are reduced. The numbers of electric and hybrid vehicles entering the system are calculated based on market penetration $\mathrm{S}$ curves, which can be described by

$f(x)=\frac{x}{\sqrt{1+x^{2}}}$

The value of $x$ in Equation (3) is arbitrary and is determined by the user to construct the most appropriate S curve. The value of $x$ is assigned for every year, from the reference year to 2050. Based on the constructed $\mathrm{S}$ curve, the final number of a certain type of vehicle entering the system in 2050 , still needs to be set by the user.
The final number of a certain type of vehicle entering the system each year, based on the constructed S curve and two boundary conditions: the number of vehicles entering the system in the reference year and that in the year 2050, is then assigned by the model. The dynamics of market penetration for every alternative vehicle category are determined by the shape of an $S$ curve. As every long term plan an $S$ penetration curve has to be occasionally modified to follow the real market conditions.

The number of conventional-fuel personal vehicles entering the system is determined by the total number of personal vehicles entering the system, which is determined by the user, and the number of alternative personal vehicles. After the total number of vehicles entering the system in the year 2050 is set, the data are linearly extrapolated from the reference year. This extrapolation is performed by determining the increase or decrease in specific car ownership (car/capita). In the EDT model, all demographic data are imported from the Croatian Bureau of Statistics. Finally, the number of conventional-fuel personal vehicles entering the system is calculated as follows:

$N_{i} c^{z}=\left(n_{i}^{z}-\Sigma N_{i} a^{z}\right)^{*} C n$

Using market penetration $S$ curves provides the best possibility of phasing out certain conventional-fuel technologies and the most probable dynamics of alternative personal vehicles entering the transportation system. The $x$ coefficients in Equation (3) can be set to have the most suitable dynamics for market penetration. In the results section, examples of this interaction between alternativeand conventional-fuel personal vehicles are provided.

\subsection{Rail transport}

In terms of energy, rail transport is divided into two forms of fuel sources, electrical energy and diesel fuel. In this case, their interaction is a major part of modelling the energy demand in this subsector. The final energy demand is calculated as the sum of the consumptions of the two fuel types.

$R^{z}=\sum_{i=1}^{n} e_{i}^{z}$

Each fuel type group is calculated based on the number of vehicles (locomotives, trains or pulling carts) and their consumption and efficiency.

$e_{i}^{z}=\sum_{i=1}^{n}\left(m_{i}^{z} \cdot a_{i}^{z} \cdot b_{i}^{z} \cdot q_{i}\right) / 10^{6}$

The total number of each type of rail vehicle is calculated based on the current number and the possibilities of new vehicles entering and old vehicles exiting the system.

For rail vehicles using diesel fuel:

$m_{i} d^{z}=m_{i} d^{z-1}-m n_{i}^{z}$

For vehicles using electrical energy:

$m_{i} e^{z}=m_{i} e^{z-1}+c s \cdot m n_{i}^{z}+m m_{i}^{z}$

The number of rail vehicles entering the system is calculated based on future projections regarding new tracks that are going to be built, switching from one-track railways to double-track railways and switching from non-electrified tracks to electrified tracks. The equation that calculates the number of new rail vehicles entering the system and technological switching between diesel vehicles and electrical vehicles is a function of these three mentioned parameters. 


\subsection{Air transport}

The fuel types used for air transport are reduced to only kerosene in this model; although synthetic fuel can also be substituted for kerosene. To specify and divide air transport in a more detailed way, the EDT model uses three types of aircraft to determine the total energy demand of the whole subsector: turboprop, singleaisle and wide-body aircraft. Energy consumption is calculated based on the usage, consumption and energy efficiency of all three types of aircraft.

$A^{z}=\sum_{i=1}^{n}\left(k_{i}^{z} \cdot c n_{i} \cdot q k_{i}^{z}\right) / 10^{9}$

When calculating values regarding mileage and time spent in usage per day, the model operates with physically maximum possible values, although boundary conditions can be set based on the current or future expected situation.

$k_{i}^{z}=l_{i}^{z} \cdot p_{i}^{z}$

The EDT model leaves space for both input data as well as all boundary conditions to be modified, making it applicable to other transport systems.

\subsection{Sea and river transport}

When looking at energy balances in this subsector, which have a strong international component, bunker fuel is discarded from the energy point of view. The EDT model calculates energy consumption in all inland river transportation and coastal sea transportation.

$S^{z}=S r^{z}+S s^{z}$

The primary fuels consumed in this subsector are diesel and heavy fuel oil. This version of the EDT model has the capability for fuel switching with the introduction of biofuels. The calculation of fuel consumption in the base reference year and future energy demand is made based on two methodologies, depending on the available data. River transport is calculated based on actual power $(\mathrm{kW})$ and specific consumption, while coastal transport is calculated based on actual number of vessels and their specific consumption.

$r^{z}=p^{z} \cdot p p^{z} \cdot C p^{z}$

$s^{z}=B^{z} \cdot b b^{z} \cdot C j^{z}$

The EDT model calculates the number of future vessels as a function of total passenger seats, average passenger seats per a vessel, total passenger carried and average occupancy.

\subsection{Public urban transport}

The public transport subsector is composed of vehicles that run on electricity, diesel, biodiesel and CNG (compressed natural gas). It
Table 2

Passenger kilometres and tonne kilometres in the reference year [23].

\begin{tabular}{|c|c|c|c|c|c|c|c|c|}
\hline \multicolumn{2}{|c|}{$\begin{array}{l}\text { Railway } \\
\text { transport }\end{array}$} & \multicolumn{2}{|c|}{$\begin{array}{l}\text { Road } \\
\text { transport }\end{array}$} & \multicolumn{2}{|c|}{$\begin{array}{l}\text { Seawater } \\
\text { and coastal } \\
\text { transport }\end{array}$} & \multirow{2}{*}{$\begin{array}{l}\text { Inland } \\
\text { waterway } \\
\text { transport } \\
\text { tkm }\end{array}$} & \multicolumn{2}{|c|}{$\begin{array}{l}\text { Air } \\
\text { transport }\end{array}$} \\
\hline pkm & $\mathrm{tkm}$ & pkm & tkm & pkm & tkm & & pkm & $\mathrm{tkm}$ \\
\hline 1810 & 3312 & 4093 & 11,042 & 491 & 142,972 & 843 & 1945 & 3 \\
\hline
\end{tabular}

is important to note that in this classification, suburban electrified rail transport is excluded and included in the rail transport model. Public urban transport energy consumption and future demand are calculated by summing the consumptions of all previously mentioned fuels. When calculating energy consumption, the main parameters are vehicle usage, consumption and energy efficiency. Again, the model has the capability of introducing boundary conditions such as the possible daily kilometres that a certain vehicle can run or the energy efficiency index determining minimum and maximum fuel consumption.

$U_{i}^{z}=u_{i}^{z} \cdot f e_{i} \cdot t_{i}^{z}$

Technology switching in the public urban transport is modelled among different fuel types, with a special emphasis on replacing diesel fuel with biofuels and compressed natural gas, at least in the short run. Fuel consumption is directly related to the fleet condition and is a function of different fuel mixtures.

\subsection{Modal split among described subsectors}

Modal split among subsectors in EDT model is calculated through passenger kilometres and tonne-kilometres. Based on historical information or user inputs, the energy value of a passenger or tonne kilometre is calculated by the model for every subsector. Afterwards, the number of passengers or tonne kilometres is calculated for every year based on the previously calculated energy consumption of every subsector, making it possible to set up different scenarios. Modal split is best calculated if major infrastructural works can be foreseen, such as building high-speed rail in certain parts of the country. If such information is not available, these plans can be simply defined using a scenario approach for future scientific research. In the results section, the possible energy savings due to modal split between road air and rail transport is presented and analysed.

\section{Results and discussion}

In this section, the major results and conclusions obtained by the EDT model are presented. Setting the reference year is the first step in calibrating the EDT model. For this case, 2008 was chosen as the reference year. The basic input data for all five sub-modes are given in Tables 1 and 2 . The most common energy indicators used in the model construction are shown in Table 3.

Most of the input data used in the EDT model are directly taken from the Croatian Bureau of Statistics [23] and the Croatian energy

Table 1

Transport of passengers and goods in the reference year [23].

\begin{tabular}{|c|c|c|c|c|c|c|c|c|}
\hline \multicolumn{2}{|c|}{ Railway transport } & \multicolumn{2}{|l|}{ Road transport } & \multicolumn{2}{|c|}{ Seawater and coastal transport } & \multirow{2}{*}{$\begin{array}{l}\text { Inland waterway } \\
\text { transport } \\
\text { Goods carried, } \\
\text { ('000 t) }\end{array}$} & \multicolumn{2}{|l|}{ Air transport } \\
\hline $\begin{array}{l}\text { Passengers } \\
\text { carried, ('000) }\end{array}$ & $\begin{array}{l}\text { Goods } \\
\text { carried, ('000 t) }\end{array}$ & $\begin{array}{l}\text { Passengers } \\
\text { carried, ('000) }\end{array}$ & $\begin{array}{l}\text { Goods carried, } \\
\text { ('000 t) }\end{array}$ & $\begin{array}{l}\text { Passengers } \\
\text { carried, ('000) }\end{array}$ & $\begin{array}{l}\text { Goods } \\
\text { carried, ('000 t) }\end{array}$ & & $\begin{array}{l}\text { Passengers } \\
\text { carried, ('000) }\end{array}$ & $\begin{array}{l}\text { Goods carried, } \\
\text { ('000 t) }\end{array}$ \\
\hline 70,961 & 14,851 & 62,064 & 110,812 & 12,861 & 30,768 & 6415 & 2329 & 5 \\
\hline
\end{tabular}


Table 3

Most common energy indicators used when constructing the EDT model [26].

\begin{tabular}{|c|c|c|c|c|}
\hline $\begin{array}{l}\text { Road transport of goods } \\
\text { per tonne-km (toe/tkm) }\end{array}$ & $\begin{array}{l}\text { Energy consumption of road } \\
\text { transport per equivalent } \\
\text { car (toe/careq) }\end{array}$ & $\begin{array}{l}\text { Specific consumption } \\
\text { of cars }(1 / 100 \mathrm{~km})\end{array}$ & $\begin{array}{l}\text { Unit consumption of air } \\
\text { transport (toe/passenger) }\end{array}$ & $\begin{array}{l}\text { Energy efficiency gains } \\
\text { in transport since } 2000 \text { (\%) }\end{array}$ \\
\hline 0.064 & 0.78 & 7.29 & 0.057 & 13.8 \\
\hline
\end{tabular}

Table 4

Main properties of the Croatian road transport in the reference year [23].

\begin{tabular}{|c|c|c|c|c|c|c|}
\hline \multicolumn{7}{|c|}{ Number of road vehicles } \\
\hline \multirow[t]{3}{*}{ Total } & \multicolumn{6}{|l|}{ Out of total } \\
\hline & \multirow[t]{2}{*}{ Motorcycles } & \multicolumn{2}{|c|}{ Passenger cars } & \multirow{2}{*}{$\begin{array}{l}\text { Light } \\
\text { vans }\end{array}$} & \multirow[t]{2}{*}{ Buses } & \multirow{2}{*}{$\begin{array}{l}\text { Goods } \\
\text { vehicles }\end{array}$} \\
\hline & & Total & $\begin{array}{l}\text { Privately } \\
\text { owned }\end{array}$ & & & \\
\hline 2021936 & 63357 & 1535280 & 1365228 & 9597 & 5099 & 170704 \\
\hline \multicolumn{7}{|c|}{ Number of road vehicles entering the transport system } \\
\hline Total & Motorcycles & Passenger cars & Light vans & Buses & Gooc & vehicles \\
\hline 144518 & 8811 & 95697 & 402 & 391 & 1314 & \\
\hline
\end{tabular}

Table 5

Air transport information for the reference year [23].

\begin{tabular}{|c|c|c|c|c|}
\hline \multicolumn{5}{|c|}{ Aircraft fleet } \\
\hline $\begin{array}{l}\text { Total } \\
\text { number }\end{array}$ & $\begin{array}{l}\text { Passenger } \\
\text { seats }\end{array}$ & $\begin{array}{l}\text { Net aircraft loading } \\
\text { capacity, }(\mathrm{kg})\end{array}$ & $\begin{array}{l}\text { Aircraft-kilometre } \\
\text { flown, ('000) }\end{array}$ & $\begin{array}{ll}\text { Number of } \\
\text { working flights }\end{array}$ \\
\hline 19 & 2415 & 272021 & 22307 & 32586 \\
\hline \multicolumn{5}{|c|}{ Passenger and freight data } \\
\hline \multicolumn{2}{|c|}{$\begin{array}{l}\text { Passengers } \\
\text { carried, ('000) }\end{array}$} & $\begin{array}{l}\text { Passenger- } \\
\text { kilometres, (mln) }\end{array}$ & $\begin{array}{l}\text { Freight } \\
\text { carried, (t) }\end{array}$ & $\begin{array}{l}\text { Tonne- } \\
\text { kilometres, ('000) }\end{array}$ \\
\hline \multicolumn{2}{|c|}{$\begin{array}{l}\text { Total International } \\
\text { traffic }\end{array}$} & $\begin{array}{l}\text { Total International } \\
\text { traffic }\end{array}$ & $\begin{array}{l}\text { Total International } \\
\text { traffic }\end{array}$ & $\begin{array}{l}\text { 1 Total International } \\
\text { traffic }\end{array}$ \\
\hline \multicolumn{2}{|c|}{23291775} & 19451768 & 51363369 & 30382495 \\
\hline
\end{tabular}

balance [26]. Statistically, the Croatian transport sector is well covered, which allows an end-use level of modelling (Tables 4, 5 and 6).

For the purposes of this paper, four different energy demand scenarios are presented and analysed. The first scenario involves frozen energy efficiency throughout the modelling period. This is done solely for the purpose of comparing possible energy savings in case of different energy efficiency mechanisms.

The next scenario involves the implementation of current EU legislation regarding the energy efficiency of internal combustion engines. Of course, this scenario would be applicable if indeed EU legislation was enforced in Croatia. Because it is expected that Croatia will enter the EU in the second half of 2013, this seems like a realistic option.

The third scenario presents the option of the electrification of personal vehicles till the year 2050 . This is a very interesting scenario because it offers insight into possible energy savings and reduced dependence on foreign fossil fuels in case Croatia decides to switch to electrification. This would present a significant impact on the country's electricity demand, meaning new infrastructure and technologies both on the transmission and distribution side [24].

Finally, the fourth scenario presents an even better energy efficiency solution because it implies a further modal split from road and air transport to rail in the forthcoming period. For the purposes of this paper, the start of the modal split has been set to the year 2015.

In Fig. 2 all four energy demand scenarios can be seen. If left with no technology development, the energy demand of the Croatian transport sector would reach $168 \mathrm{PJ}$, which is an increase of almost $82 \%$ compared to that of the reference year. If an increase in the energy efficiency of personal vehicles is applied, which is in line with the $\mathrm{EU}$ regulation on $\mathrm{CO}_{2}$ emissions, the energy consumption in the year 2050 can be lowered by 33\%. Further improvements, in terms of energy consumption, that are in line with the electrification of the personal vehicles fleet, could lead to an additional $26 \%$ in energy savings when compared to the scenario implementing EU energy efficiency legislation. Finally, if an additional modal split is added to the electrification scenario, an additional $15 \%$ of energy can be saved in the year 2050. Comparing the zero efficiency scenario with the modal split scenario, the total possible energy savings in the Croatian transport sector in the year 2050 can reach nearly 99 PJ, or $59 \%$.

As probably the most interesting scenario, here the electrification scenario is described in greater detail. All four scenarios were calculated based on the same number of personal vehicles in the system, which would account for approximately 2 million vehicles in the year 2050 (Fig. 3). Based on the methodology presented in Section 2.1, the total number of personal vehicles was calculated by accounting for the entrance and exit of personal vehicles in the system. As a safety check, specific car ownership (cars/capita) was used, which, as shown in Fig. 3, indicated an increase of $50 \%$ in specific car ownership from the reference year to year 2050. To have fewer parameters and variables in all four scenarios presented on Fig. 2, a reference scenario was used for all subsectors while the road transport subsector was modified.

In the reference scenario, the main focus is on technology switches among different vehicles present in the system, which has a direct influence on energy demand. The energy efficiency issue is also considered, which influences future energy demand significantly, as shown in Figs. 4 and 5.

Based on the reference scenario, the only two subsectors that experience an increase in energy consumption, beyond future energy efficiency improvements, are public and air transportation. The increase in energy consumption for public transportation is due to a great motivation for public transport improvement, which is in line with the increased fleets, routes and total number of

Table 6

Urban transport data for the reference year [23].

\begin{tabular}{|c|c|c|c|c|c|c|c|}
\hline \multicolumn{4}{|l|}{ Trams } & \multicolumn{4}{|l|}{ Buses } \\
\hline Number & Passenger seats & $\begin{array}{l}\text { Kilometres } \\
\text { travelled, ('000) }\end{array}$ & $\begin{array}{l}\text { Passengers } \\
\text { carried, ('000) }\end{array}$ & Number & Passenger seats & $\begin{array}{l}\text { Kilometres } \\
\text { travelled, ('000) }\end{array}$ & $\begin{array}{l}\text { Passengers } \\
\text { carried, ('000) }\end{array}$ \\
\hline 430 & 61,487 & 18,634 & 207,868 & 1129 & 108,864 & 71,300 & 200,997 \\
\hline
\end{tabular}




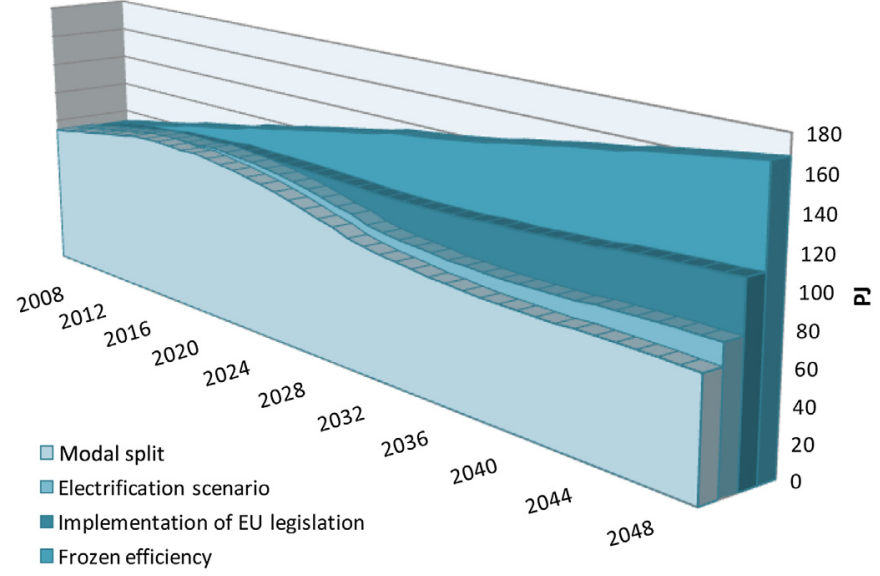

Fig. 2. Four different long-term energy demand scenarios.

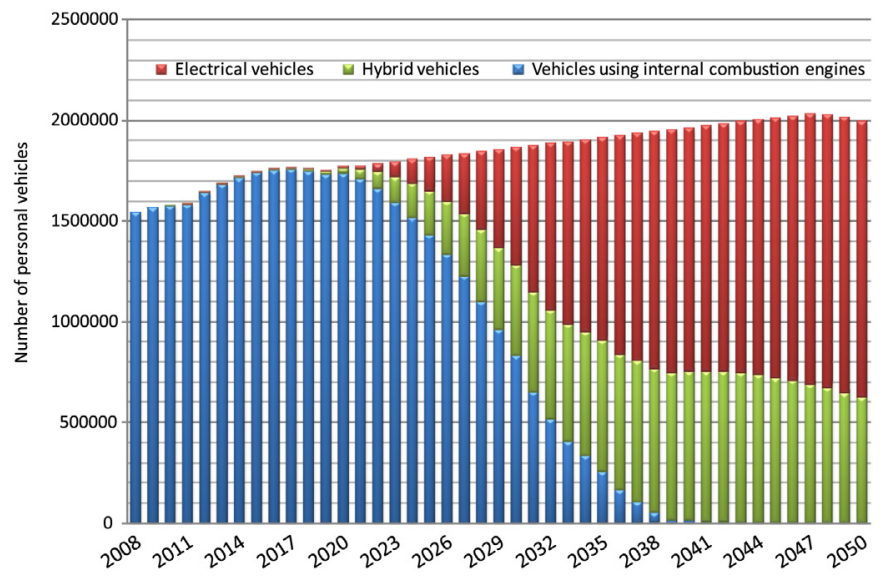

Fig. 3. Personal vehicle distribution according to year.

passengers using this type of transportation. Air transportation increases as a result of a constant Croatian strive towards the expansion of the tertiary sector (Fig. 5). Interesting results are shown in Fig. 4, specifically, a constant decrease in energy demand in the rail subsector. Despite a significant increase in traffic, the continuous electrification of this subsector leads to a decrease in its long-term energy demand.

Perhaps the most interesting parameter when comparing the electrification scenario with the other scenarios is the fleet size regarding electric personal vehicles and its effect on the total final energy demand of the transport sector.

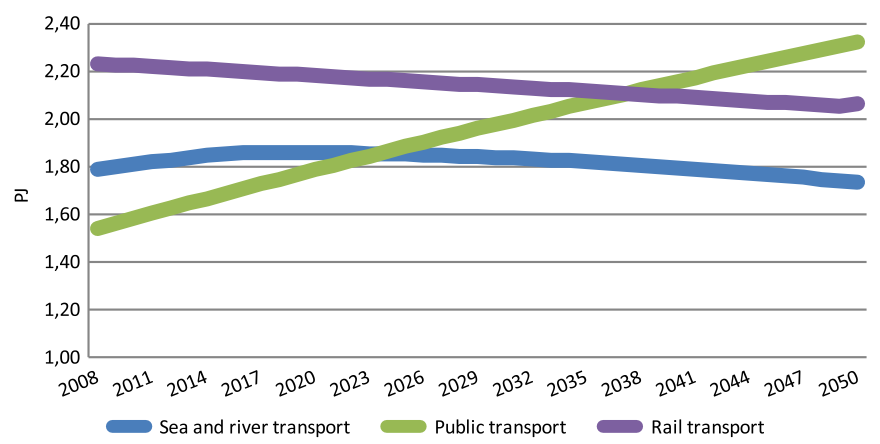

Fig. 4. The EDT model reference scenario for rail, public and sea and river transport.

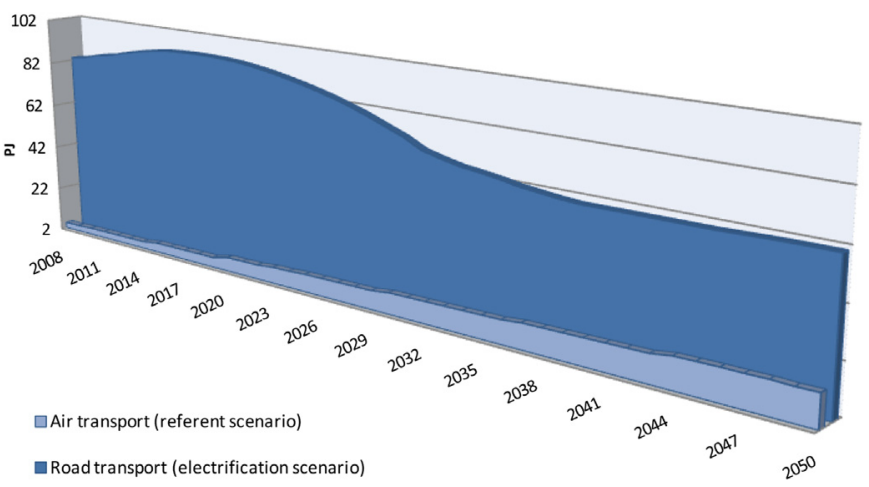

Fig. 5. The EDT model reference scenario for air transport and electrification scenario for the road transport.

The dynamics of alternative personal vehicle penetration and the total number of such vehicles in the system are shown in Figs. 6 and 7. The highest market penetration of electrical vehicles is assumed to occur by the end of the 2020s, while hybrid vehicle penetration is assumed to occur almost an entire decade earlier (Fig. 6).

To increase specific car ownership by $50 \%$, the electrification scenario assumes a steady increase in the number of electrical personal vehicles till 2050 to almost 1.4 million. In the same scenario, plug in hybrid vehicles would account for around 600,000 vehicles (Fig. 7). In the year 2045, a phase out of conventional hybrid vehicles can be seen, with plug-in vehicles being the only hybrid vehicles left in the system. In the electrification scenario, hybrid vehicles, together with electric vehicles, become the backbone of personal vehicle road transportation after 2040. The main intention of Fig. 7 is to show potential trends in the implementation of electric vehicles based on a different scenario approach.

In Fig. 8, the different fuel ratios of the entire transportation sector are presented for the electrification scenario. The electrification of personal vehicles substantially affects the total final

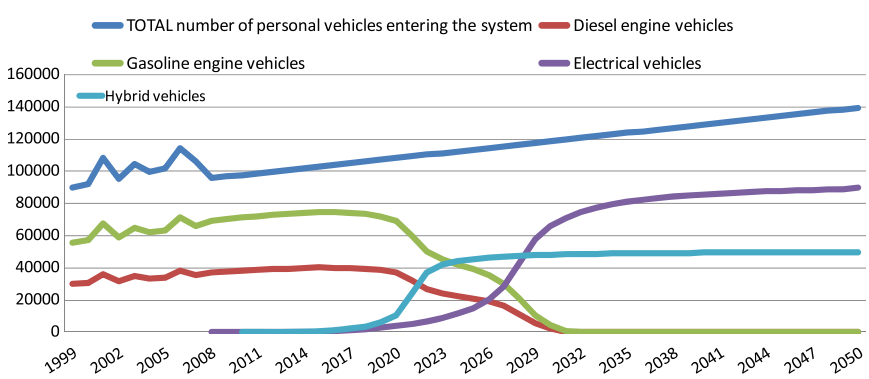

Fig. 6. New vehicles entering the system every year in the electrification scenario.

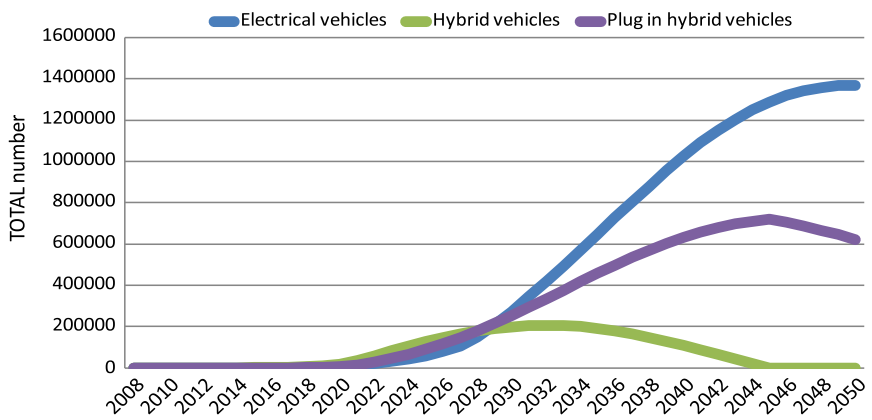

Fig. 7. Number of electric and hybrid personal vehicles in the system for the electrification scenario. 


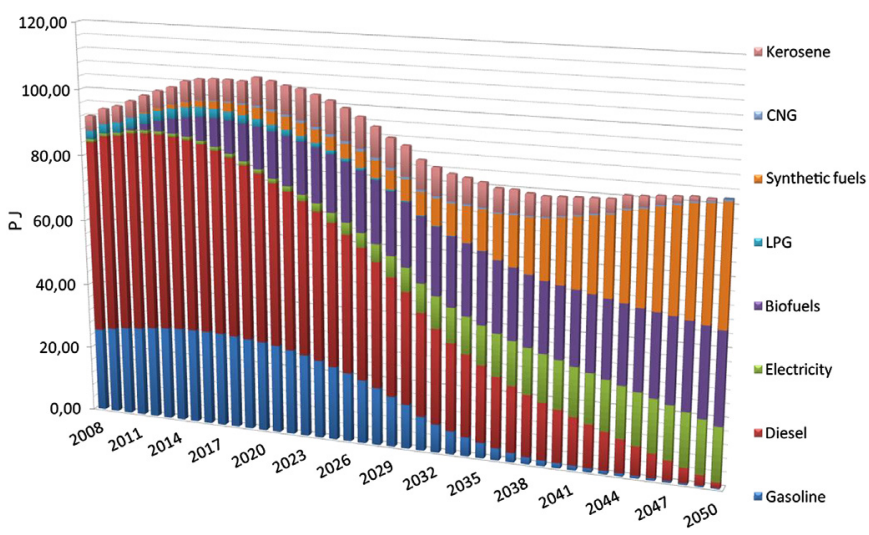

Fig. 8. Fuel ratio in personal vehicles subsector for electrification scenario.

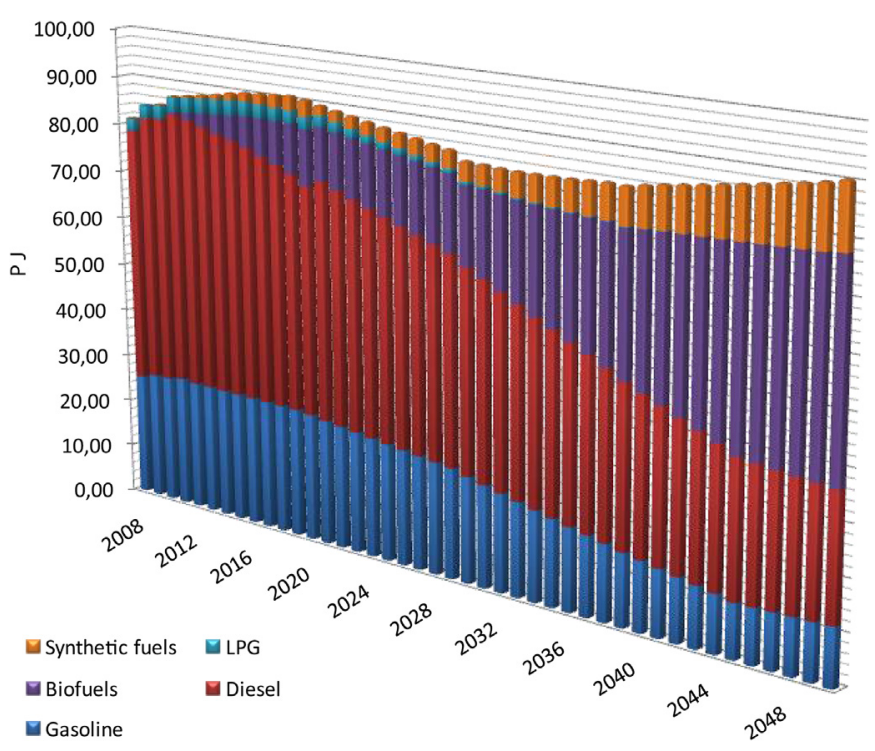

Fig. 9. Fuel ratio of road transport subsector without electrification but with implemented EU legislation on energy efficiency.

energy demand. In Fig. 9, the fuel mix of only road transport, without any electrification of the personal vehicles subsector, is presented. When comparing Figs. 8 and 9, it can be concluded that the road transportation alone, without any electrification, but with implemented EU legislation on energy efficiency, exhibits $32 \%$ higher energy consumption in the year 2050 than the entire transportation sector for the electrification scenario.

One of the main questions not considered in this study is that regarding how to satisfy all of the energy needs of the transport subsectors that are not viable for electrification. One of the logical assumptions would be to implement existing biofuels or emerging synthetic fuels [25]. The issue of biofuels in Croatia can be a sensitive one. The main issue is the actual potential of biofuels and their sustainability in Croatia. In future transport systems, the most difficult subsectors to model are the ones that are not likely to be electrified. For the purposes of this paper, most of those subsectors

Table 7

Volumetric energy density of biofuels and their comparison to compatible fossil fuels $(\mathrm{MJ} / \mathrm{l})$.

\begin{tabular}{llll}
\hline Diesel & Biodiesel & Gasoline & Ethanol \\
\hline 36 & 33 & 32 & 21 \\
\hline
\end{tabular}

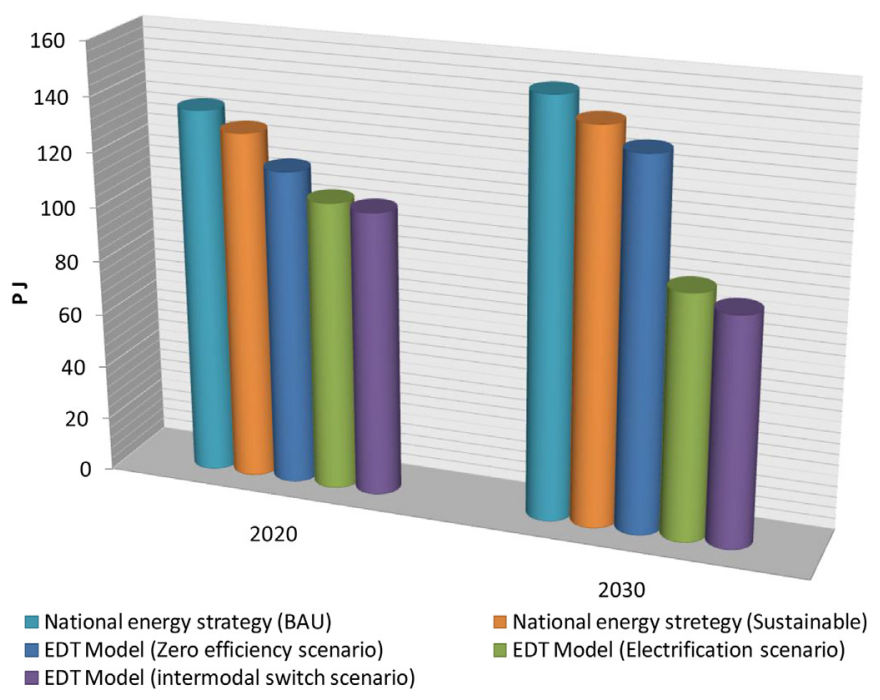

Fig. 10. Comparison of results calculated with EDT model and the Croatian national energy strategy.

are "transferred" to biofuels or synthetic fuels. Ultimately, the EDT model is scenario-based; thus, the transition rate to biofuels or synthetic fuels can be set by the user.

In Fig. 8, biofuels comprise biodiesel, ethanol and biomethane. When the EDT model calculates the substitution of biofuels for fossil fuels, it compensates for the lower energy value of biofuels from one side, but it also takes into consideration higher specific consumption of biofuels. Unfortunately, when calculating the whole transport subsector specific consumption cannot be imported into the model as an input data. It has to be calculated by known parameters for the reference year, such as vehicle fleet properties and total final energy consumed. Data shown in Table 3 is used just as guidance and a boundary condition in the process of calculating actual values, dependent on a certain fuel form in the reference year. As input data, the parameters from Table 7 are imported into the EDT model.

The introduction of synthetic fuel is most likely in the air transport subsector; however, it is also possible in other forms of transport.

To compare EDT model results with the national energy strategy, two target years were chosen. In Fig. 10, three different EDT model scenarios are compared with two national energy strategy scenarios for the years 2020 and 2030 . The national energy strategy offers two main long-term energy demand paths, the first being the business as usual and second being the sustainable path. If we compare the two extreme scenarios (national energy strategy (BAU) and the EDT model (modal split scenario)), we can see that for the year 2020, the EDT model calculates 22\% lower energy consumption than the national energy strategy. For the year 2030, this consumption is $44 \%$ lower. It can be concluded that different energy policies, technology improvements as well as other incentives will lead to lower national final energy demand. This is a win-win situation for the country because it allows for the further development of new technologies, new investment cycles, an increase in employment and, at the same time, it suggests lower dependence on fossil fuel imports.

\section{Conclusion}

Modelling the future energy demand of a transport sector can be very challenging and complex. The EDT model helps us analyse different legal or financial mechanisms that are directly related to 
future energy demand. To date, the EDT model has been proved to be a reliable tool for the basic assessment of the future energy demand of a transport sector. Its methodology can be applied to other energy systems and transport sectors, considering the specific factors and boundary conditions, such as modal structure or bunker fuel exclusion. The results show that electric vehicles will play a key role in future transport systems, allowing for significant savings in final energy demand. This means more vehicles and kilometres driven with lower final energy demand. The difference between the national energy strategy's (BAU) projected final energy demand and that projected by the EDT model's modal split scenario for 2020 is $30 \mathrm{PJ}$, and in 2030, the difference is $68 \mathrm{PJ}$. One of the conclusions drawn from the presented results is that the Croatian national energy demand scenarios regarding the transport sector must be considered with some reservation because bottomup modelling shows a certain room for energy efficiency improvements, which would subsequently lead to energy savings.

\section{Acknowledgement}

The financial support from the Croatian Science Foundation through the "ICT-aided integration of Electric Vehicles into the Energy Systems with a high share of Renewable Energy Sources" project is gratefully acknowledged.

\section{Nomenclature}

$D_{i} \quad$ energy demand of a certain category of road transport, PJ

$E_{i} \quad$ number of vehicles of a certain category of road transport

$M_{i} \quad$ fuel consumption of vehicles of a certain category of road transport, $1 / 100 \mathrm{~km}$

$C v_{i} \quad$ fuel consumption energy efficiency index

$P_{i} \quad$ usage of vehicles of a certain road transport category, $\mathrm{km} /$ year

$\mathrm{Cm}_{i} \quad$ usage efficiency index

$Q_{i} \quad$ heating value of a fuel type that a vehicle is using, MJ/l

$z \quad$ year for which the calculation is made

$N_{i} \quad$ vehicles entering the system

$C f_{i} \quad$ vehicles exiting the system

$N_{i} \mathrm{C} \quad$ conventional personal vehicles entering the system

$n_{i} \quad$ total number of personal vehicles entering the system

$\mathrm{Cn}$ share of a certain type of conventional personal vehicle in the total number of personal vehicles entering the system every year

$N_{i} a \quad$ alternative personal vehicles entering the system

$K_{i} \quad$ newly registered alternative vehicles

$C_{i} \quad$ newly registered alternative vehicles historical index

$R \quad$ energy demand of rail transport, $\mathrm{PJ}$

$e_{i} \quad$ energy consumption of a certain fuel type, PJ

$m_{i} \quad$ number of a certain vehicle type

$a_{i} \quad$ average yearly consumption of a certain vehicle type, $\mathrm{t} /$ year

$b_{i} \quad$ energy efficiency index of a certain vehicle type

$q_{i} \quad$ heating value of fuel used by a certain vehicle, $\mathrm{MJ} / \mathrm{kg}$

$m_{i} d \quad$ number of diesel vehicles in the system

$m n_{i} \quad$ number of diesel vehicles exiting the system

$m_{i} e \quad$ number of electrical vehicles in the system

$m m_{i} \quad$ new electrical vehicles entering the system

cs technology switch index

A energy demand of air transport, $\mathrm{PJ}$

$k_{i} \quad$ kilometres flown, km

$\mathrm{Cn}_{i} \quad$ yearly fuel consumption, $\mathrm{kg} / \mathrm{km}$

$q k_{i} \quad$ heating value of fuel, $\mathrm{MJ} / \mathrm{kg}$

$l_{i} \quad$ yearly kilometres flown of a certain aircraft type, $\mathrm{km}$

$p_{i} \quad$ number of aircraft

\section{References}

[1] Vuk B, Vukman S, Karan M, Fabek R, Zivkovic S, Maricevic M, et al. Annual energy report - energy in Croatia. Zagreb, Croatia: Ministry of Economy, Labour and Entrepreneurship; 2009.

[2] Mathiesen BV, Lund H, Karlsson K. 100\% renewable energy systems, climate mitigation and economic growth. Appl Energy 2011;88:488-501.

[3] Xiaoyu Y, Crookes RJ. Reduction potentials of energy demand and GHC emissions in China's road transport sector. Energy Policy 2009;37:658-68.

[4] Adaptation and upgrade of Croatian energy strategy - green book. Zagreb, Croatia: Ministry of Economy, Labour and Entrepreneurship; 2008.

[5] Sa'ad S. Improved technical efficiency and exogenous factors in transportation demand for energy: an application of structural time series analysis to South Korean dana. Energy 2010;35:2745-51.

[6] Al-Ghandoor A, Samhouri M, Al-Hinti I, Jaber J, Al-Rawashdeh M. Projection of future transport energy demand of Jordan using adaptive neuro-fuzzy technique. Energy 2012;38:128-35.

[7] Limanond T, Jomnonkwao S, Srikaew A. Projection of future transport energy demand of Thailand. Energy Policy 2011;39:2754-63.

[8] Yu S, Zhu K. A hybrid procedure for energy demand forecasting in China Energy 2012;37:396-404

[9] Johansson $\mathrm{B}$. Will restrictions on $\mathrm{CO}_{2}$ emissions require reductions in transport demand? Energy Policy 2009;37:3212-20.

[10] Reichl J, Kollmann A. The baseline in bottom-up energy efficiency and saving calculations - a concept for its formalisation and a discussion of relevant options. Appl Energy 2011;88:422-31.

[11] Zhang S, Jiang K, Liu D. Passenger transport modal split based on budgets and implication for energy consumption: approach and application in China. Energy Policy 2007;35:4434-43.

[12] Parikh KS, Karandikar V, Rana A, Dani P. Projecting India's energy requirements for policy formulation. Energy 2009;34:928-41.

[13] Eom J, Schipper L. Trends in passenger transport energy use in South Korea. Energy Policy 2010;38:3598-607.

[14] Ćosić B, Krajačić G, Duić N. A 100\% renewable energy system in the year 2050: the case of Macedonia. Energy 2012;48(1):80-7.

[15] Segurado R, Krajačić G, Duić N, Alves L. Increasing the penetration of renewable energy resources in S. Vicente, Cape Verde. Appl Energy 2011;88:466-72.

[16] Lund H, Kempton W. Integration of renewable energy into the transport and electricity sectors through V2G. Energy Policy 2008;36:3578-87.

[17] Bauer M, Mar E, Elizalde A. Transport and energy demand in Mexico: the personal income shock. Energy Policy 2003;31:1475-80.

[18] Turton H. Sustainable global automobile transport in the 21st century: an integrated scenario analysis. Technol Forecasting Social Change 2006;73:607-29.

[19] Kyle P, Kim SH. Long-term implications of alternative light-duty vehicle technologies for global greenhouse gas emissions and primary energy demands. Energy Policy 2011;39:3012-24.

[20] McFarland JR, Reilly JM, Herzog HJ. Representing energy technologies in topdown economic models using bottom-up information. Energy Econ 2004;26: 685-707.

[21] Schneider RD, Duić N, Bogdan Ž. Mapping the potential for decentralized energy generation based on renewable energy sources in the Republic of Croatia. Energy 2007;32:1731-44.

[22] Banister D, Hickman R. Transport futures: thinking the unthinkable. Transport Policy 2012. http://dx.doi.org/10.1016/j.tranpol.2012.07.005

[23] Državni zavod za statistiku (Croatian Bureau of Statistics). $<$ www.dzs.hr $>$ [accessed 12.06.12].

[24] Lund H, Andersen AN, Østergaard PA, Mathiesen BV, Connolly D. From elec tricity smart grids to smart energy systems - a market operation based approach and understanding. Energy 2012;42:96-102.

[25] Mathiesen BV, Lund H, Nørgaard P. Integrated transport and renewable energy systems. Utilities Policy 2008;16:107-16.

[26] Energy efficiency indicators in Europe-ODYSSEE-MURE. <www.odysseeindicators.org $>$; 2010 [accessed 15.04.12]. 